\title{
An Efficient Utilization of Blackboard Ally in Higher Education Institution
}

\author{
Ahmad Almufarreh, Muhammad Arshad” and Sameer Hassan Mohammed
}

\author{
Deanship of e-Learning and Information Technology, Jazan University, Alburj Campus, Jazan, Gizan 82812, Kingdom of \\ Saudi Arabia \\ *Corresponding Author: Muhammad Arshad. Email: msarshad@jazanu.edu.sa \\ Received: 11 February 2021; Accepted: 23 March 2021
}

\begin{abstract}
Without the constraints of time and place, e-learning can offer a strong learning environment. The notion of e-learning has taken on a new sense with the advent and popularization of mobile devices and ubiquitous computing, enabling students to have access to several diverse opportunities for communicating with e-learning programs. Around the same time, it has prompted the course's planners to select the most suitable technology from among the various innovations required for the storing and dissemination of information representation. As a Learning Management System (LMS), the Blackboard system now has a recognized role in the knowledge management of the education system. Blackboard offers effective and easy-to-use instructional teaching, correspondence, and assessment systems. Blackboard Ally works to create more open content for interactive classes and helps institutions create a more balanced experience of teaching and learning. Blackboard Ally is a unique application that easily blends with the Virtual Learning Environment (VLE) and runs directly within the workflows currently used by administrators, instructors, and students. This analysis is intended to explore the successful utilization and assessment of Blackboard Ally among academics in the Jazan University, Kingdom of Saudi Arabia. The key purpose of this study is to examine how administrators, faculty members, and students use Ally for Blackboard LMS's functionality across online classes to analyze both the learning process and the success of the individual. A critical review of the literature, utilization, and examination of Blackboard Ally shows a good range of scholarly opinions, research, hypotheses, models, and experiences about the simulated learning environment. According to our knowledge and literature review, this is the first research article to evaluate the implementation and utilization of the Ally tool by Blackboard LMS.
\end{abstract}

Keywords: Learning management system; blackboard; artificial intelligence; blackboard ally; higher education institution; virtual learning environment

\section{Introduction}

Education is an essential factor in building a strong nation and serves as the backbone of every nation in the world. The basic concept of education is that it is a form of learning in which the practices, information,

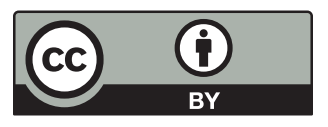

This work is licensed under a Creative Commons Attribution 4.0 International License, which permits unrestricted use, distribution, and reproduction in any medium, provided the original work is properly cited. 
and skills of a group are conveyed through study, teaching, and/or training from one generation to the next. Though education most commonly takes place under the supervision of others, it may also be self-taught. In this way, learning can follow two tracks, firstly, as students interact together and speak about ideas and conceivable ideas, and secondly, on subjects of study, as associated with various students far and wide [1,2].

The exponential advancement in information technology has revolutionized teaching and learning methods in educational environments. Numerous reports indicate that the amount and standard of higher education e-learning programs such as "Blackboard" have improved dramatically over the years. To communicate effectively with each other via chat, podcasts, discussion boards, and file sharing, students and teachers enter this virtual learning environment together. In reality, Blackboard's implementation has revolutionized the conventional teaching system, resulting in one form of effective educational information management [3].

Researchers claim that this method of information management consists of the use of codified knowledge that creates structured representations of information entities, enabling process integration, decision-making, and retrieval of information. In translating implicit information to formal or codified knowledge, Blackboard goes a long way to eliminating the causes of knowledge loss owing to memory limitations. The use of e-learning software such as "Blackboard" tends to reduce the cost of reproducing information, contributing to the successful management of knowledge. Although e-learning has benefits for students, learners, and institutions, it raises fundamental concerns about the learning process $[4,5]$.

\section{Literature Review}

Literature suggests that online learning increases and requires less time to process information. The development of new Information and Communication Technology (ICT) teaching opens up the prospect of improving the standard of higher education. Indeed, the pedagogically capable use of these tools will offer a real advance in the personification of the educational method, helping to overcome the expense of the teaching framework of mass reproduction [6,7]. The informatization of education is a significant threat to contemporary higher education in a humanitarian context, acting as a kind of measure of its pedagogical potential. The use of digital, virtual, and network information systems, high-power computers of the new decades, as well as the growth of the Internet (and in particular the 'fast Internet') are especially important developments in education [8,9].

For third world countries where literacy rates are very low, e-learning resources and technology is nothing less than a blessing. On the other hand, tools and technologies have the potential to meet catering needs for all levels of education, regardless of time and place. E-learning tools and technologies can involve large numbers of people in learning; besides, it makes classes interactive and saves learning time and effort $[10,11]$. In terms of its efficiency, effectiveness, and economics, the approach has a universal application. The instructor and the learner are taking advantage of the facility. In addition to the scarcity of a quality teacher concerning the large population, which is a roadblock in schooling, we know that conventional teaching requires immense infrastructure and significant investment that is usually lacking [12].

\subsection{Emerging Technologies for Learning and Development}

More than ever before, learners are flooded with obstacles and have quick access to endless quantities of knowledge. How can social media, mobile apps, and, well, the whole Internet compete with Learning and Development (L\&D)? The key is not to compete, but to adapt and take advantage of evolving developments in technology that impact learning and development [13]. The institutions will typically provide instructor-led training (ILT) or interactive instructor-led training (vILT) and the normal experience of desktop eLearning. Institutions in higher education can integrate learning solutions to create something that leverages the changing learning and development environment [14]. Educational 
innovations have been evolving at unprecedented rates for over a decade, but many educational institutions struggle to recognize and leverage these technologies. Augmented reality (AR) is one of the main developments in technology right now and when AR ready smartphones and other gadgets become more available around the globe, it can only become bigger. The Internet of Things (IoT) refers to a system of interrelated, internet-connected devices that can capture and transmit data without human interference over a wireless network [15]. Nowadays, cloud computing is the new and most popular technology and many businesses are making a move into its benefits. Cloud computing resolve the lack of infrastructure issue, which is the biggest challenge for many institutes are facing [16]. A podcast is an episodic collection of downloadable audio files of spoken words that a user can download for easy listening on a personal computer. Streaming software and podcasting platforms offer a simple and integrated way for multiple podcast channels and listening systems to handle a private consumption queue. Fig. 1 illustrates some of the most important and influential emerging technologies in education technology that the management of educators must know/understand to provide students with a better education.

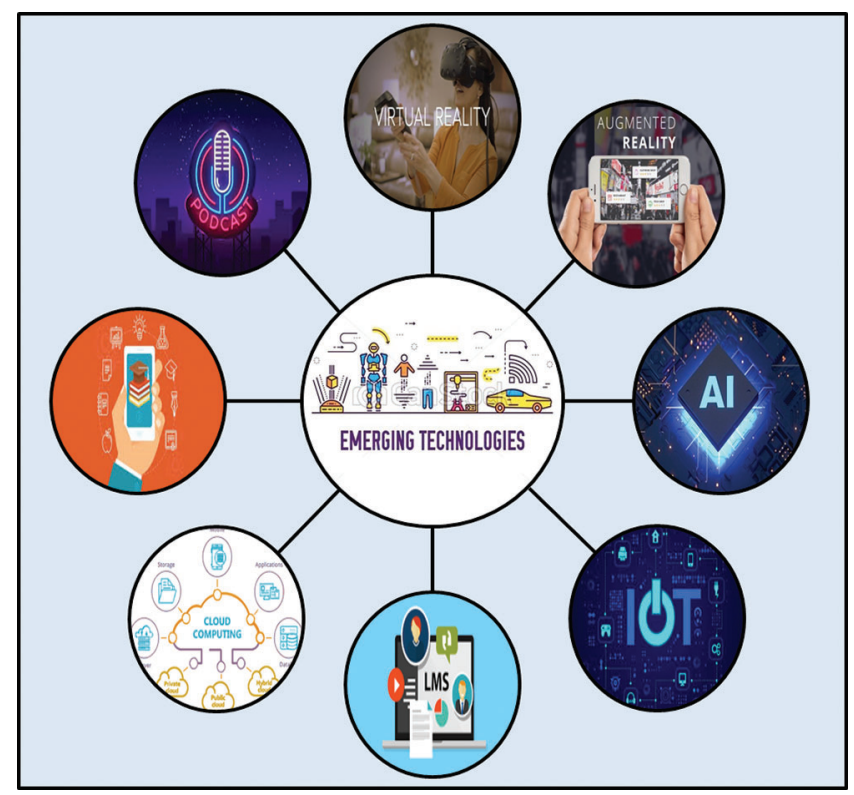

Figure 1: Prominent Emerging Technologies for Learning and Development

Deep Blue, an artificial intelligence developed by IBM, beat Garry Kasparov, the world chess champion, in May 1997, marking a major symbolic breakthrough in computational science. Artificial intelligence will also detect certain conditions faster and more reliably than physicians in the field of medicine. In the meantime, a pair of chatbots developed by Facebook to easily interact with each other creating a disconcerting code language to communicate [17]. As a young technology, it's apparent that AI's complete capabilities are yet to appear. It is also evident that there will be more uses for online education as they expand and become more available. By acquiring the advantages of this new technology, the e-Learning environment will potentially expand at a dramatic pace AI can influence e-Learning in five ways including: Real-Time Questioning, Natural Language Processing, Improve Accessibility, Generate Fresh Content, and Personalize Learning.

\subsubsection{Real-Time Questioning}

Artificial intelligence will serve as a virtual teacher and respond on the fly to questions. AI would help learners build new environments for scenario-based learning that are immersive. Besides, by creating 
complex responses within a situation, AI may benefit educators. It can consider more variables, providing a more practical scenario, instead of following a pre-planned script.

\subsubsection{Natural Language Processing}

The sub-field of AI that is based on helping computers to comprehend and process human languages is Natural Language Processing or NLP. You will pose questions and explain your concerns in the language you want when you incorporate your eLearning courses with an AI assistant. This would not only make it even easier to read, but also save a lot of time and make learning much more engaging and successful.

\subsubsection{Improve Accessibility}

To change the lives of people with disabilities, Artificial Intelligence has also been used. AI can be used to translate spoken language into captions and translations, making it easier for the hearing impaired to understand the issue. AI can also serve as a personal companion to people who struggle with mobility challenges by listening to voice commands. This would allow them to invest in the e-learning course and job goods much more.

\subsubsection{Generate Fresh Content}

To build or produce new information, Artificial Intelligence is already being studied. AI is now being used to produce answers leveraging current tools for online instruction. AI will be used soon to create the whole material of an eLearning course, relieving instructional designers of a massive work load.

\subsubsection{Personalize Learning}

It is a very common approach in corporate training to offer the same type of content to any single learner. For a teacher to listen to and fulfill the desires of any learner, it may indeed be very daunting. But when everybody has their personality and speed of learning, this one-size-fits-all solution is surely not suitable. AI can be used to monitor an individual's past success and use the knowledge to adjust the current learning content, thereby creating a tailored learning experience. AI will monitor the progress of learners within an eLearning course, which can help determine the places where each learner needs expertise, and alter the content accordingly [18].

\subsection{Ally for Learning Management System}

Blackboard LLC was formed in 1997 as a consultancy company to offer professional specifications for online learning applications by two curriculum advisors, Matthew Pittinsky and Michael Chasen. The IMS Global Learning Consortium, a nationwide non-profit institution under Educause's National Learning Technology Program, was contracted with Blackboard LLC. The vision of Blackboard was to provide a user-friendly way for instructors to place course data on the Internet, including syllabi, comparison pages, and research guides $[19,20]$. Blackboard Ally works on creating more open content for interactive classes and helps institutions create a more balanced experience of teaching and learning. Blackboard Ally is a unique approach that easily blends with the Virtual Learning Environment (VLE) and runs directly within the workflows currently used by students and teachers Approaches to instruction provide a range of ways of teaching that could inspire and promote self-guided pedagogy. Today, the use of e-learning programs such as Blackboard has been introduced by the educational institutions of the world as part of their instructional activities. In the effective use of e-learning tools, machine knowledge is a critical influence on faculty members [21].

Traditionally, most providers of educational technologies concentrate on the usability of the networks themselves, whilst the content is frequently a black box. This reflected a clear and very serious void that was in the way of all students having an inclusive learning environment. By reflecting on the content within those frameworks, Blackboard Ally strives to eliminate the void. Blackboard Ally was created to 
assist institutions to consider and resolve the usability of the material of this course in a manner that supports all students. The idea that accessibility should not be attributed only to disabilities is one of the driving factors behind the development. Accessibility should be about allowing everyone better access and enhancing the quality of their educational experience [22]. In three particular ways, Blackboard Ally accomplishes this:

Alternative Formats: Blackboard Ally runs resources for teacher courses through an accessibility checklist that tests for basic accessibility problems. Ally can produce a variety of alternate formats such as audio, mobile-friendly JavaScript, ePub, electronic braille, and translated versions for the instructor's material using sophisticated Machine Learning algorithms and make them available to all students in the course. These alternate formats provide the student with an instant, more open starting point and allow students the option of how they want their material to be consumed.

Instructor Input \& Advice: Ally will also offer in-context feedback to teachers on the usability of their course material and guidance on how to address the accessibility problems found, leveraging the knowledge obtained from the accessibility checks. This is aimed at increasing consciousness among instructors about usability and helping them make their content more available.

Institutional Reporting: Blackboard Ally offers an institution-wide accessibility report of course content that enables deep insight and comprehension of how the institution operates and evolves from a course content accessibility point of view, which is the first time that institutions have been able to provide a detailed overview of all their course content. This will assist the institution to assess success and determine additional measures to enhance the usability of its course materials.

\section{Theoretical Fundamentals}

This study uses qualitative and quantitative knowledge by endorsing the Online Course Evaluation model to explore the efficient utilization of Ally integrated software with Blackboard LMS. The various types of Blackboard that can be used are shown in Fig. 2: Static Blackboard, Dynamic Blackboard, and Integrative Blackboard. The model defines three forms of Blackboard Static, Dynamic, and Interactive Blackboard, this study focused on Integrative Blackboard. The functionality found in the interactive Blackboard can be used in the Integrative Blackboard. The analysis of online course evaluation can be classified into three types: Analysis as an Administrator, Analysis as an Instructor, and Analysis as a Student. The characteristics of Integrative Blackboard are:

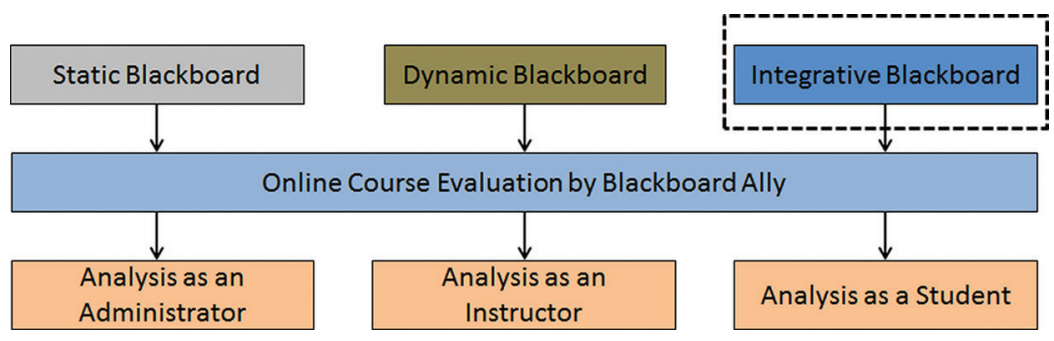

Figure 2: Online Course Evaluation Framework

a) Enable Blackboard to be combined with other external applications/software.

b) Combine with other software's like Ally, Respondus, and Prometric test engines.

c) Allow students to acquire proper format course material, take exams, and attend online seminars.

d) Support hybrid classroom sessions, with a few learners online and several on-campus.

e) Address some limitations like plagiarism, learner's dedication, data security, and confidentiality.

f) Protect students in their educational phase. 
The primary contribution of this study is to examine the efficient utilization of Blackboard Ally integrated software for online courses during the semester. The research objectives of this study are:

a) Testing the overall level of compliance with online course contents.

b) Determining the areas of the greatest risk by type of content.

c) Defining if the tool will allow us to develop targeted risk mitigation.

\section{Methodology}

The goal of this study was to investigate the use of Blackboard Ally for online courses at Jazan University in undergraduate higher education programs. Researchers analyzed the teaching and learning impacts of Blackboard Ally incorporation using a mixed-method with quantitative and qualitative approaches.

\subsection{Statistical Analysis of Blackboard Ally}

Qualitative analysis fundamentally means to measure something by its quality rather than quantity. Qualitative analysis explores how to describe something, very often, without using numbers or numerical expressions to describe those things. Qualitative analysis works with descriptions, feelings, thoughts, perceptions, and attempt to understand motivations and behaviors. The alternative is quantitative analysis; calculation of quantity rather than consistency. The quantitative analysis discusses facts, indicators, figures, percentages, and evidence. In public relations, both qualitative and quantitative researches are extremely relevant.

\subsection{Participants Population}

Full-time faculty members and students of the Faculty of Arts and Humanities of Jazan University were the target population for this study. A total of 85 faculty members and 263 students from the three departments of the Faculty of Arts and Humanities were overviewed by survey questionnaires, which is more than $75 \%$ participant of the Faculty of Arts and Humanities community. All faculty members and students were asked to fill and submit the questionnaire. However, 24 cases have been identified as outliers and incomplete so they have been excluded from the dataset to minimize inaccurate population inferences. Therefore the actual sample of faculty members and students was 81 and 243 respectively. To achieve the fundamental goal of the research study, faculty members and students ought to be computer literate and have an Internet facility.

\subsection{Data Collection}

To devise a solid case, study design requires the eliciting of data from multiple sources is vital. To this end, the data for this study was collected by making use of the Administrator reports of the courses' lectures by Blackboard Ally and an anonymous survey questionnaire of the faculty members and students.

Anonymous surveys are an appropriate method employed to collect exploratory, explanatory or descriptive types of data. Qualitative surveys offer a data collection tool used to elicit information about a sample population with regards to their experiences and meaning-making process related to a specific topic. The survey was carried out online, and the questionnaire was posted online to 348 participating faculty members and students via the Blackboard system, which collected structured data through openended questions and Likert form alternative ordinate. The goal of the survey was to determine the effectiveness of Blackboard Ally features and components in improving academic performance and satisfaction. The total survey responses were 324 , giving a $100 \%$ response. 


\section{Results and Discussions}

This section introduces the findings of the study dependent on the gathered information to investigate utilizing Blackboard as a learning management system and the impact of academic performance and improvement by Ally integrative tool at Jazan University, KSA.

\subsection{Demographic Analysis}

Demographic research requires items that help one to quantify societies' measurements and dynamics. These methods have primarily been developed to study human populations, but are extended to a variety of areas where researchers want to know how populations of social actors can change across time. Because of inequalities between faculty members in terms of ethnicity, educational background, and computer literacy, it was expected that there would be certain discrepancies in the use of Blackboard.

\subsubsection{Participants}

Results presented in Fig. 3 illustrate the usage of Blackboard Ally among faculty members and students. It can be concluded that the use of technology overall is not department-specific; therefore there was no effect of departments on the use of Blackboard Ally.

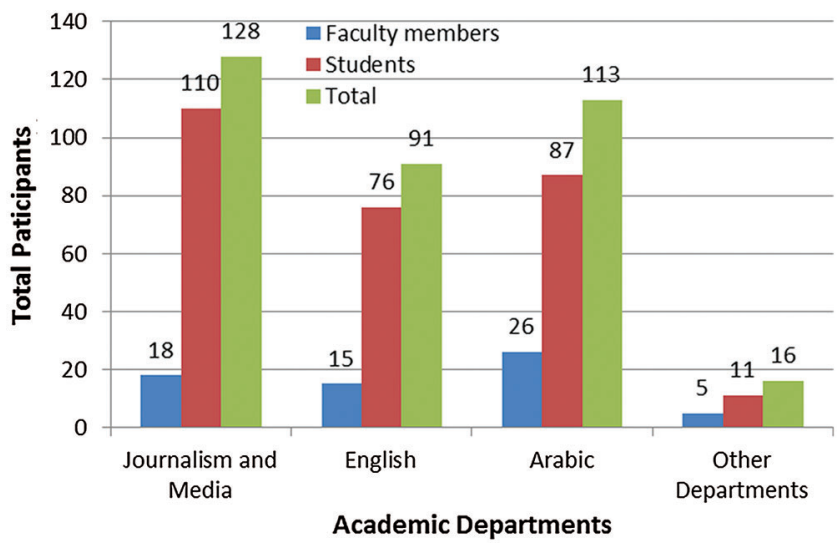

Figure 3: Total Participants from Departments

\subsubsection{Computer Literacy}

Results presented in Fig. 4 illustrate the different categories of faculty member's computer proficiency. In higher education, where hi-tech developments have a transformational effect on learning and teaching, the expanded innovative proficiency among staff and students are of focal significance. The significance of educators' ICT abilities has been perceived in a variety of nations, with numerous specialists opposing that "Instructors should have the option to deal with the innovation with self-assurance." One of the primary methods of reasoning for the advancement of instructors' ICT-related abilities is the improvement of students' learning results and the advancement of their ICT proficiency. This measurement could be credited to the way that they are much mature than the digital natives and may not be responsive to grasping new technology straightforwardly.

In all manner of areas, from projectors and televisions and computer laboratories and student computers, technology has failed to make a way into the classroom. It is also important that learners learn to use technology to enhance their work and train for jobs in a world where computers have become as ubiquitous as pencil and paper, in addition to enhancing the way students are educated. Computer learning systems give students the ability to extend their horizons to gain knowledge that in the 
conventional classroom they may not get the chance to develop. Becoming technologically literate ensures that learners acquire computational knowledge, learn laws of authorship, such as copyright and plagiarism, understand how to access material online, and learn social awareness when engaging on social networks.

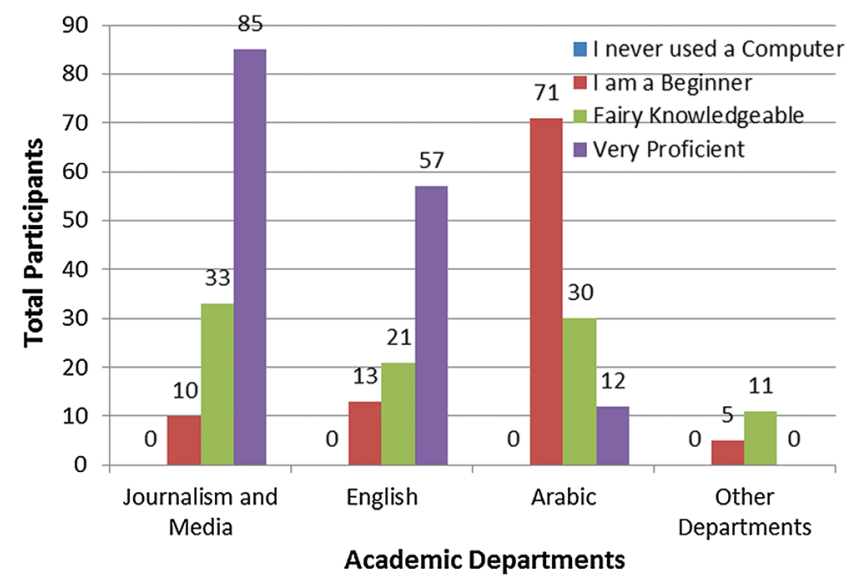

Figure 4: Computer Literacy

Besides the computer literacy of the faculty members and students, the computer proficiency of the authors is also significant in order to understand the learning management system and its tools in an efficient way. All authors are currently working in the Deanship of e-Learning and Information Technology of the Jazan University and they are expert and confident in computer proficiency because of their education background and professional working environment of Information Technology (IT).

\subsection{Blackboard Ally Utilization}

Using e-learning programs such as "Blackboard" tends to reduce the expense of reproducing knowledge, contributing to the successful management of knowledge. Although e-learning has benefits for students, learners, and universities, it raises fundamental concerns about the learning process. Blackboard Ally is a platform that interacts with your Learning Management System (LMS) effortlessly to gain insight into the usability of your institution [23]. This section explains the utilization of Blackboard Ally by Administrator, faculty members, and students that contains the following parameters: Analysis as an administrator, Analysis as an instructor, and Analysis as a student.

An administrator can do the following tasks with Blackboard Ally: gain an appreciation of the success of usability in your institution, tackle usability and target both teachers and content proactively, view patterns in usability and comprehensive diagrams to track enhancement, provide the usability report of institution-wide course material, Provide ratings on usability, offer suggestions to the teacher about how the usability score can be enhanced, and generate alternate download formats for students.

As an instructor to gauge the usability of materials, Blackboard Ally works smoothly with your Learning Management System (LMS). Ally gives advice and tips on permanent changes to the usability of the content [24]. These are: receive reviews on your content usability and boost usability of the material with Ally's stepby-step guidance, and provide your insight into the usability of your content.

Finally, Blackboard Ally produces alternate files that students can access more effectively [25]. Alternative files provide readable text for screen readers, captioned images, and content that's easy to access. 


\subsubsection{Analysis as an Administrator}

Blackboard Ally offers an institution-wide usability report of course content that allows for deep insight and comprehension of how the university works and evolves from the point of view of the accessibility of course content. This study serves to document success and can serve to recognize problem areas and identify programs that can further help to enhance the institution's usability.

Fig. 5 illustrates the semester accessibility report of the academic semester of the fall semester of the academic year 2020-21 of Jazan University, KSA, where 10,231 registered courses are using the Blackboard Ally tool. The total content created by these courses is 126,284 and finally, the overall accessibility score of these courses and course contents is $49 \%$ which is a very good score according to the Ally group. Tab. 1 explains the satisfaction level of the administrator of the analysis of the registered courses by Blackboard Ally.

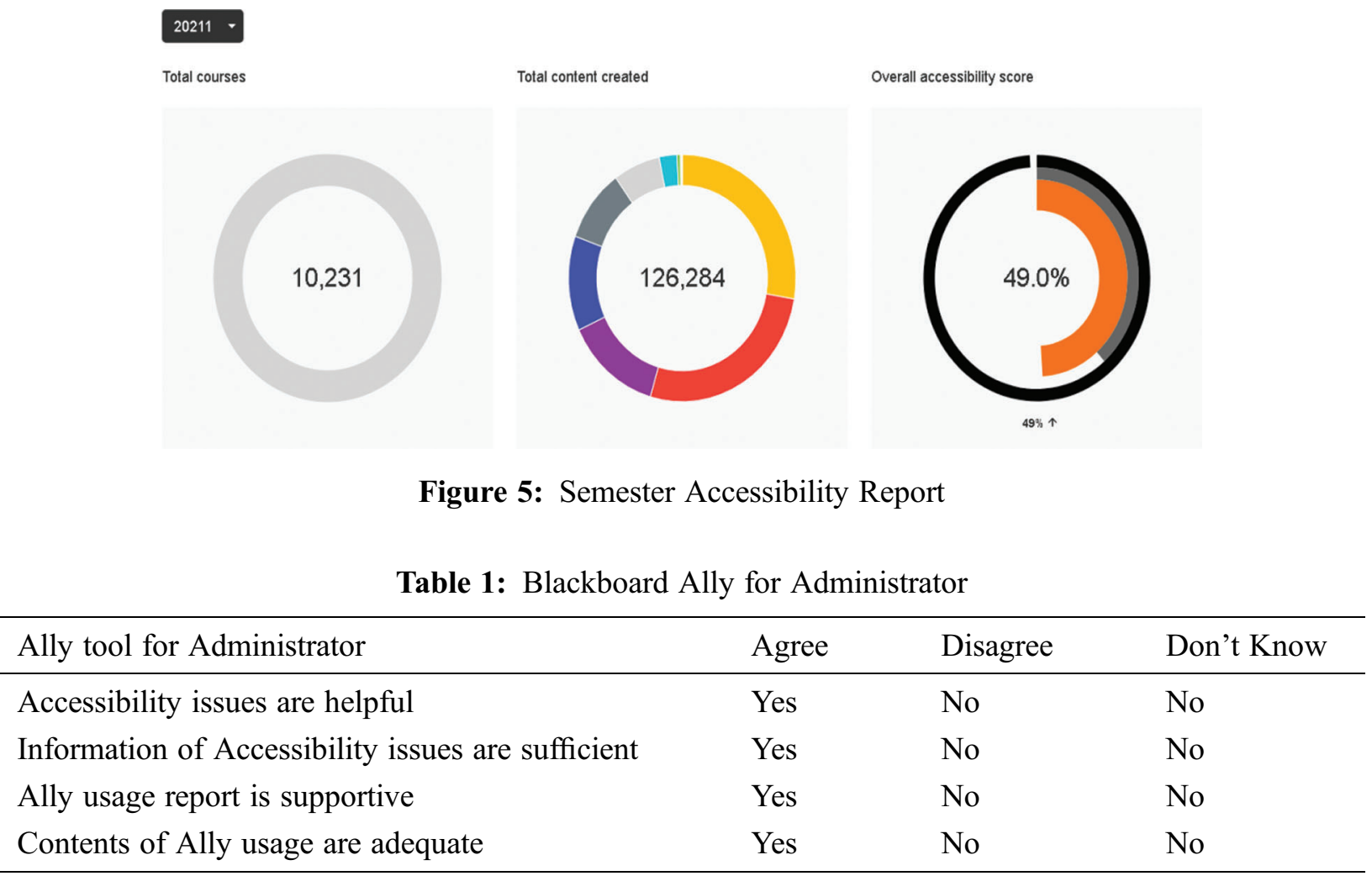

Fig. 6 illustrates the severe issues of the fall 2021 registered courses are 4,685 and 82 for scanned documents and malformed documents respectively. Scanned documents mean that the content of a PDF file is scanned but not in Optical Recognition Character (OCRed).

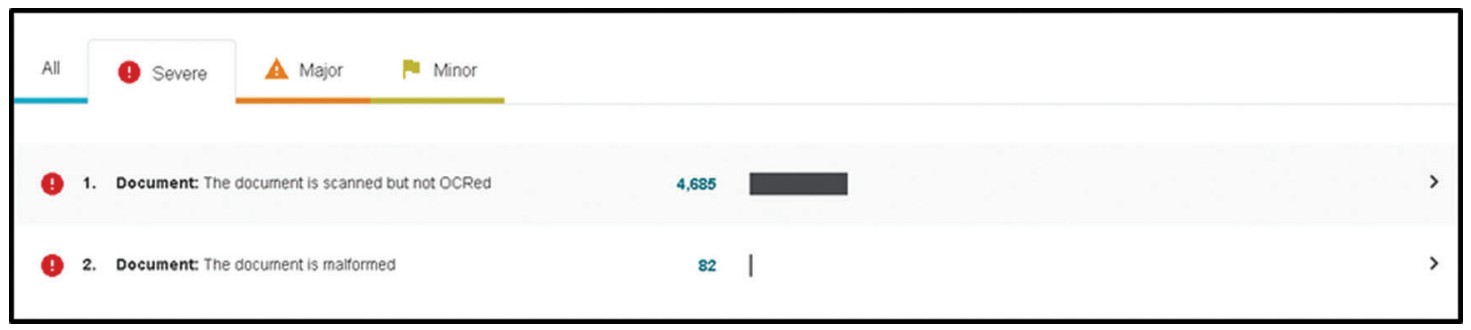

Figure 6: Severe Accessibility Issues 
Tab. 2 demonstrates the detailed course analysis college-wise. The College of Science is the leading college that has 2,011 total sections/courses but only 374 section/courses have files. The total numbers of files in these sections are 24,475 which are downloaded by students 1,126 times through the Ally tool. The College of Design and Architecture has fewer sections/courses among all colleges and only 88 sections/courses have the files. The total numbers of files in 88 sections/courses are 2,462 and students downloaded these files 243 times during their courses via Ally. Besides these colleges, the College of Computer Science and Information Technology had 12,520 files in their 323 sections/courses and these 323 files were downloaded 870 times by students.

Table 2: Detailed Course Analysis by College

\begin{tabular}{llllll}
\hline Colleges & $\begin{array}{l}\text { Total } \\
\text { Sections/ } \\
\text { Courses }\end{array}$ & $\begin{array}{l}\text { Number of } \\
\text { Sections } \\
\text { have Files }\end{array}$ & $\begin{array}{l}\text { Number of } \\
\text { Sections } \\
\text { haven't Files }\end{array}$ & $\begin{array}{l}\text { Total Files in the } \\
\text { Sections of this } \\
\text { Faculty }\end{array}$ & $\begin{array}{l}\text { Number of Files } \\
\text { Downloaded by } \\
\text { Student using Ally }\end{array}$ \\
\hline Medicine & 610 & 564 & 46 & 1,052 & 125 \\
$\begin{array}{l}\text { Engineering } \\
\begin{array}{l}\text { Design and } \\
\text { Architecture }\end{array}\end{array}$ & 1,404 & 223 & 1,181 & 16,271 & 560 \\
$\begin{array}{l}\text { Computer Science } \\
\text { and Information } \\
\text { Technology }\end{array}$ & 976 & 88 & 274 & 2462 & 243 \\
\begin{tabular}{l} 
Science \\
\hline
\end{tabular} & 2,011 & 323 & 652 & 12,520 & 870 \\
\hline
\end{tabular}

\subsubsection{Analysis as an Instructor}

Most institutions include students with different needs today, both physical and interactive. Alternative models provide everyone with a better ability to view the data they need in the manner they need it or like to. All students can achieve the same learning goals with alternative formats, using tools that are designed to meet the particular student's needs.

\subsubsection{Frequency of Blackboard Ally Usage by Participants}

The research work has shown that faculty members and students have been participating in the utilization of Blackboard Ally frequently in their teaching and learning process within the academic semester. Earlier preparation on Blackboard Ally utilization was given to all faculty members and students during orientation sessions and they are completely mindful of the advantages of utilizing this integrative tool.

The Blackboard utilization results proved that most of the faculty members use Blackboard to expedite their courses at least 2-3 times each week or more as illustrated in Fig. 7.

\subsubsection{Academic Evaluation and Satisfaction on Blackboard Ally Usage}

The degree to which a student, teacher, or institution has accomplished its short or long-term educational objectives is academic success or "academic achievement." The social and economic development of the country is directly linked with student academic performance.

The academic achievement plays an important role in producing the best quality graduates who will become great leaders and manpower for the country, and are thus responsible for the country's economic and social development. During this study, the survey questionnaire asked 10 questions to faculty 
members and 5 questions to students by Blackboard to consider the influence of Blackboard Ally on academic achievement and satisfaction.

The results in Fig. 8 illustrate the faculty members' attitudes and satisfaction level towards using Blackboard Ally in learning was positive and useful. The study has illustrated that the majority of the faculty members were fairly knowledgeable and proficient in computing, a precursor for the adoption of Blackboard Ally.

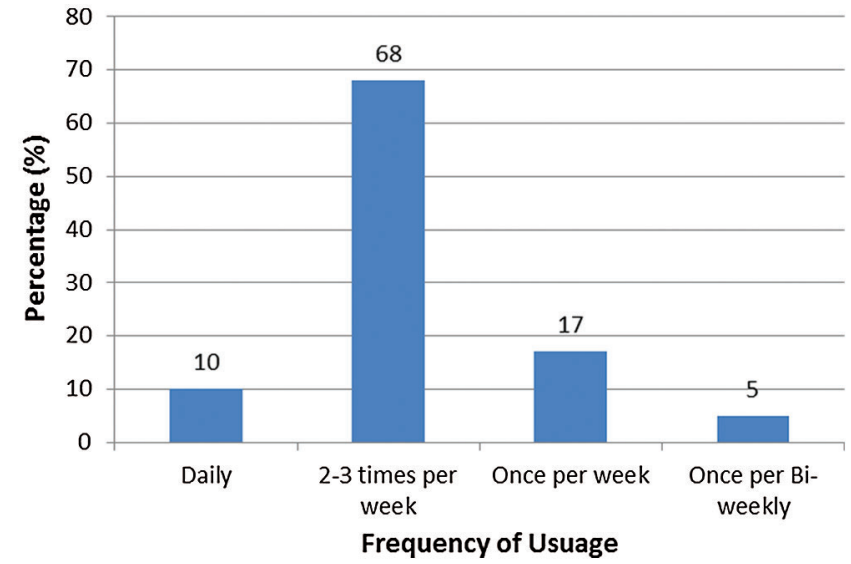

Figure 7: Blackboard Ally Usage of Frequency by Participants

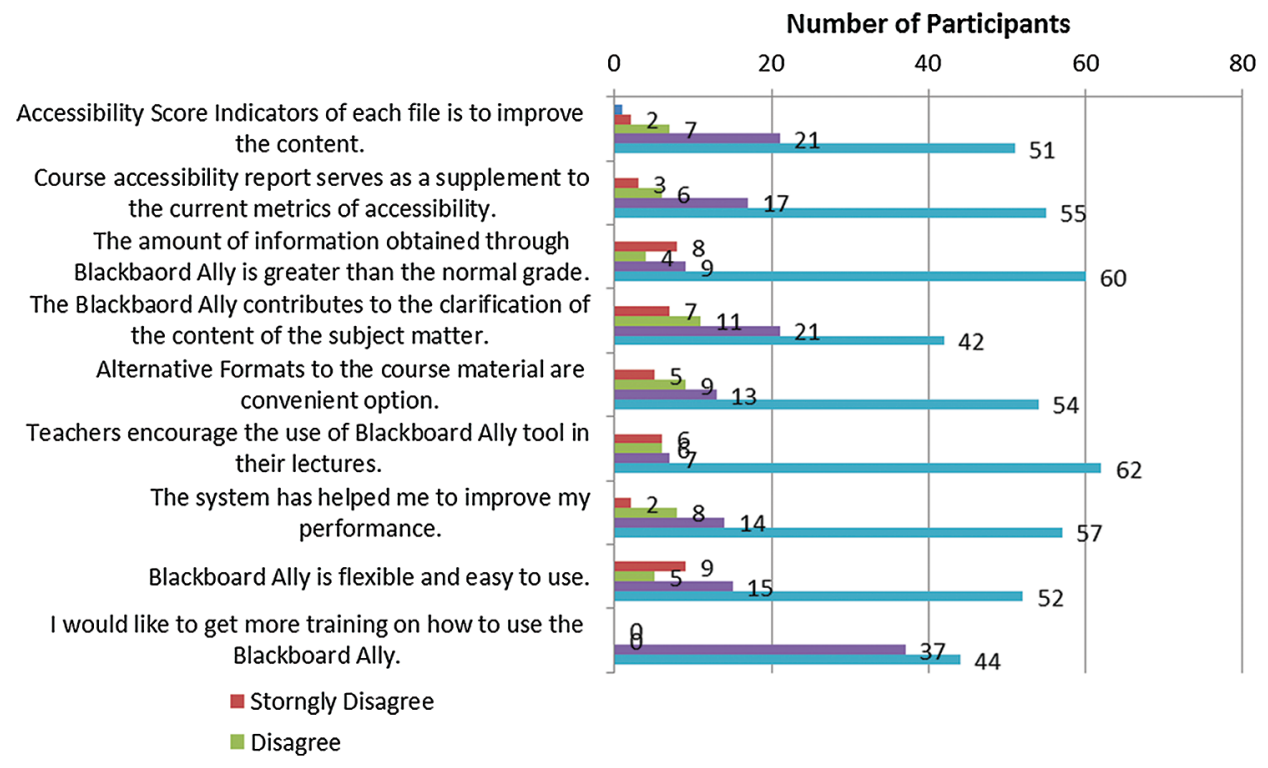

Figure 8: Academic Evaluation and Satisfaction of Instructor

\subsubsection{Analysis as a Student}

Students may ask if they ever find material that was hard to read in their courses, or would they like it to come in a different format? Nowadays, they can import alternate formats of course material directly from the institute uses Blackboard Ally. On the course material tab, you'll see an Alternate Formats or Download 
Alternative Formats link right after the course content or a file link. Alternative Formats connect opens the Download Alternative Formats dialog when chosen with the following options:

a) Tagged PDF: Structured PDF for improved use with assistive technology, Downloads to a device.

b) HTML: For viewing in the browser and on mobile devices, opens in a new browser window.

c) ePub: For reading as an e-book on an iPad and other e-books reader, Downloads to a device.

d) Electronic braille: BRF version for consumption on electronic braille displays, Downloads to a device.

e) Audio: MP3 version for listening, Downloads to device

f) BeeLine Reader: Enhanced version for easier and faster on-screen reading, Opens in the browser window.

g) Translated version: A machine-translated version of the original document, Downloads to a device.

\subsubsection{Academic Satisfaction on Blackboard Ally Usage}

Through the online and integrated classroom conversations and problem-solving, the use of integrative Blackboard increases the fundamental level of comprehension.

The findings found that integrative Blackboard means that students continue to engage in the classroom and become successful learners. Regarding the use of integrative Blackboard by students, the findings illustrate that teachers can effectively teach using integrated Blackboard tools. Fig. 9 illustrates the satisfaction level of the Faculty of Arts and Humanities student's usage of Blackboard Ally during the fall 2021 semester.

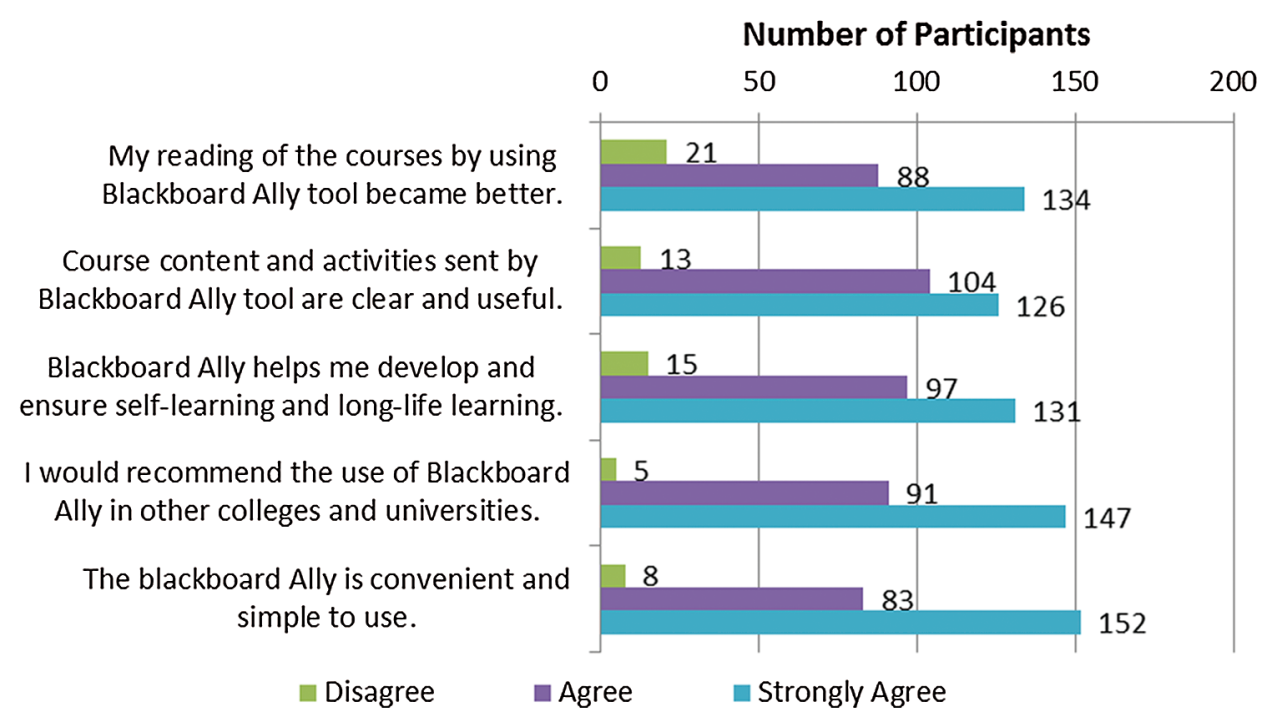

Figure 9: Satisfaction Level of Arts and Humanities Students

\subsubsection{Distribution and Usage of Alternative Formats}

Based on the original, Ally produces alternate formats to the course material. For the original materials, these formats are made available so that students can locate anything in one convenient place. There is nothing the instructor has to do; these alternative formats for the teacher are created by Ally. If the instructor wants to, for whatever reason, they will disable alternate formats for any particular content object. Tab. 3 demonstrates the distributions by alternative format type. These multiple formats are used 
for students' convenience to enhance their learning capabilities. HTML and BeeLine Reader open in the browser window and on mobile devices. The remaining format types require downloads to the device.

Table 3: Distribution by Alternative Format type

\begin{tabular}{llllllll}
\hline $\begin{array}{l}\text { Total } \\
\text { Courses }\end{array}$ & Tagged PDF & HTML & ePub & Electronic Braille & Audio & BeeLine Reader & Translated Version \\
\hline 5,358 & 9,098 & 6096 & 1,928 & 439 & 394 & 625 & 0 \\
\hline
\end{tabular}

Total sections/course in the fall 2021 semester are 5,358, among these sections/courses the Tagged PDF format type is the prominent one because of easy download to device and stress-free to learn. In this fall 2021 semester, nobody downloaded the translated version format type because the machine-translated version is not user-friendly, or perhaps the student isn't aware of this format type.

Tab. 4 demonstrates the alternative format usage over time statistics of the fall semester of the academic year of 2020-21 of Jazan University. These statistics show the weekly report of nine weeks; the sixth week of this semester has the maximum number of launches and downloads of the course files which are 5,316 and 3,038 respectively. The first week showed the minimum launches i.e. 2,272 and downloads of the files is also minimum, i.e., 1,292. Because of the semester beginning, the load of the sections/courses is not much.

Table 4: Alternative Formats Usage over Time

\begin{tabular}{lll}
\hline Weeks & Launches & Downloads \\
\hline $8 / 31 / 2020$ & 2,272 & 1,292 \\
$9 / 7 / 2020$ & 4,366 & 2,296 \\
$9 / 14 / 2020$ & 5,035 & 2,814 \\
$9 / 21 / 2020$ & 3,314 & 1,806 \\
$9 / 28 / 2020$ & 4,214 & 2,289 \\
$10 / 5 / 2020$ & 5,316 & 3,038 \\
$10 / 12 / 2020$ & 4,127 & 2,499 \\
$10 / 19 / 2020$ & 3,742 & 2,219 \\
\hline
\end{tabular}

\section{Conclusions and Future Work}

In Saudi Arabia, the advanced education system must take exceptional steps to overcome the complexities in which higher education must fulfill the country's changing requirements and fulfill the nation's dream of Crown Prince Muhammed bin Salman. In higher education, leaders have to take huge measures to satisfy the educational demands by improving performance for the best results in upcoming years. The study was designed to explore Blackboard Ally utilization by faculty members in their online courses and the effect of Blackboard Ally on academic success in the Kingdom of Saudi Arabia at Jazan University. This tool, now completely incorporated with all leading solutions in the Learning Management Framework is expanding the way it helps institutions and teachers to increase the usability of their curriculum in the digital course. The new instructor-facing course accessibility study, Using Artificial Intelligence, scans course material for accessibility problems and provides a review that includes an overall course accessibility ranking, the distribution of course content by a form of curriculum and a list of all accessibility issues. The study also lets teachers prioritize curriculum elements 
that can be fixed with minimal remediation, reducing the time taken to increase the accessibility of classes. Demographic variables of participants do not affect faculty use of Blackboard Ally. However, computer literacy contributes to statistically significant variations in the participants' responses, suggesting that Blackboard Ally use differs between faculty members and students as a result of these demographic variables. The results confirmed that a majority of faculty use Blackboard to facilitate their courses by 2-3 times per week to posting content (lecture notes, or PPT slides), online assessments and quizzes, and assignments.

In terms of functional consequences, the results of this research are deemed successful for teachers and students. The findings also provide teachers with a room to recognize the most necessary accurate Blackboard applications to maximize the students' progress in achieving the optimal learning outcomes. To extend the applicability of the creativity theory in terms of theoretical consequences, this analysis should be used, and also suggests that the use of Blackboard Ally can be described in educational settings as activities that generate creativity. The results of this study are shared with other higher learning institutions inside and outside the country to enable them to follow learning management systems such as Blackboard Learn, which will encourage them to create a competitive advantage by improving pedagogical approaches and educational results in this challenging market.

Further study is recommended to concentrate on logistical and policy concerns, including technical assistance, costs, upgradability, licenses and permits, and preservation of the campus. The recommendation is that Blackboard Ally teacher training workshops should rely specifically on how the programs seek to increase students' academic performance and achieve the desired learning results. Higher education administration should give preference to the recruitment of new faculty members with additional resources such as Blackboard Ally in their teaching and studying, and who have experience of the Learning Management System in teaching.

Funding Statement: The authors received no specific funding for this study.

Conflicts of Interest: The authors declare that they have no conflicts of interest to report regarding the present study.

\section{References}

[1] S. Ahalt and K. Fecho, "Ten emerging technologies for higher education," RENCI White Paper Series 3.1, pp. 118, 2015. [Online]. Available at: https://renci.org/wp-content/uploads/2015/02/ EmergingTechforHigherEd.pdf.

[2] M. Arshad and M. N. Saeed, "Emerging technologies for e-learning and distance learning: A survey," in Int. Conf. on Web and Open Access to Learning (ICWOAL), Dubai, United Arab Emirates, pp. 1-6, 2014.

[3] J. A. Alokluk, "The effectiveness of Blackboard system, uses and limitations in information management," Intelligent Information Management, vol. 10, no. 06, pp. 133, 2018.

[4] J. Herrington, T. C. Reeves and R. Oliver, "Online learning as information delivery: Digital myopia," Journal of Interactive Learning Research, vol. 16, no. 4, pp. 353-367, 2005.

[5] P. Rogerson-Revell, "Directions in e-learning tools and technologies and their relevance to online distance language education," Open Learning: The Journal of Open, Distance and e-Learning, vol. 22, no. 1, pp. 57-74, 2007.

[6] W. G. Bowen, "Higher Education in the Digital Age," Princeton, NJ: Princeton University Press, 2013.

[7] S. J. Daniel, "ICTs in Global Learning/Teaching/Training: Policy Brief," Moscow: UNESCO Institute for Information Technologies in Education, 2012.

[8] A. I. Shutenko, E. N. Shutenko, A. M. Alekseev-Apraksin, Y. M. Maltseva and L. S. Lychkina, "The use of modern ICT as tools for development of learning communication in the contemporary university," Revista Espacios, vol. 40, no. 15, pp. 20, 2019.

[9] I. V. Robert, "Theory and methods of education informatization (psycho-pedagogical and technological aspects)," Moscow: IRO RAE, 2007. 
[10] D. M. Bokhari, D. S. Kuraishy and S. Ahmad, "Security concerns and counter measures in e-learning systems," Int. Conf. on Computing and Systems-2010, 2015.

[11] S. Kuraishy and M. U. Bokhari, "Teaching effectively with e-learning," Int. Journal of Recent Trends in Engineering, vol. 1, no. 2, pp. 291, 2009.

[12] M. U. Bokhari, S. Ahmad, S. Alam and F. Masoodi, "Modern tools and technologies for interactive learning," Environment, vol. 13, no. 15, pp. 17-18, 2011.

[13] J. C. Lozano, "5 Emerging technology trends influencing learning and development," 2018. [Online]. Available at: https:/elearningindustry.com/trends-influencing-learning-and-development-emerging-technology.

[14] M. Arshad, S. Ahmad and F. A. Siddiqui, "Social media technologies and their benefits in higher education institutions: a survey of Jazan University," Information Technologies and Teaching Aids, vol. 65, no. 3, pp. 91-102, 2018.

[15] K. Akshay, "10 Emerging technologies in E-learning," 2019. [Online]. Available at: https://elearning.adobe.com/ 2019/03/10-emerging-technologies-e-learning/.

[16] A. S. M. Noor, M. Younas and M. Arshad, "A review on cloud based knowledge management in higher education institutions," Int. Journal of Electrical \& Computer Engineering, vol. 9, no. 6, pp. 2088-8708, 2019.

[17] L. Lynch, "4 Ways artificial intelligence will transform e-Learning," 2019. [Online]. Available at: https://www. learndash.com/4-ways-artificial-intelligence-will-transform-e-learning/.

[18] S. Kolagani, "5 Ways artificial intelligence can shape the future of e-Learning," in CommLab India Rapid eLearning Solutions, 2019. [Online]. https://blog.commlabindia.com/elearning-design/artificial-intelligenceelearning

[19] P. Bradford, M. Porciello, N. Balkon and D. Backus, "The Blackboard learning system: The be all and end all in educational instruction?" Journal of Educational Technology Systems, vol. 35, no. 3, pp. 301-314, 2007.

[20] S. Jayson, "Blackboard breaks through," The Motley Fool, 2016. [Online]. Available: www.fool.com/News/mft/2006.

[21] M. Arshad, A. Almufarreh, K. M. G. Noaman and M. N. Saeed, "Academic semester activities by learning management system during COVID-19 pandemic: A Case of Jazan University," Int. Journal of Emerging Technologies, vol. 11, no. 5, pp. 213-219, 2020.

[22] Abilitynet Tech4Good Awards, "Blackboard Ally finalist category: Inclusive design award," 2019. [Online]. Available at: https://www.tech4goodawards.com/finalist/blackboard-ally/.

[23] Blackboard Help, "Blackboard Ally for Administrator," 2020. [Online]. Available at: https://help.blackboard. com/Ally/Ally for LMS/Administrator.

[24] Blackboard, "Blackboard Ally for Instructor," 2020. [Online]. Available at: https:/help.blackboard.com/Ally/ Ally_for_LMS/Instructor.

[25] Blackboard Help, "Blackboard Ally for Student,” 2020. [Online]. Available at: https://help.blackboard.com/Ally/ Ally for_LMS/Student. 